\title{
Free Movement of Services
}

\author{
GAVIN BARRETT
}

\subsection{Introduction}

The importance of services to modern economies, including those of Ireland, Northern Ireland and the UK, can scarcely be overstated. It seems paradoxical that most attention during the negotiation of the Brexit settlement was focused squarely on trade in goods, since the economic importance of services is far greater. The Northern Ireland services sector accounts for about 75 per cent of gross added value and 80 per cent of employment. Northern Ireland exports about $£ 6.5$ billion of services: about two-thirds of these go to the UK, but approximately $£ 1.5$ billion go to the $\mathrm{EU}$, with more than $£ 1$ billion of this going to Ireland. This economic dominance of services is also reflected in the broader UK context. By 2019, service industries accounted for 80 per cent of the UK's economic output, with the UK exporting $£ 317$ billion of services to the EU and importing $£ 217$ billion worth. ${ }^{1}$ In Ireland, too, the services industry is economically key, generating turnover of more than $€ 217$ billion. Here, too, it is by far the biggest employer, employing more than 774,000 people. From an international perspective, this is unsurprising. Services represent on average about two-thirds of the economic output in developed economies and about 70 per cent of that of the EU. ${ }^{2}$

Liberalized trade in services is more difficult to achieve than in goods, largely because trade in services is far more complex. Services exist in a variety of forms and are delivered in a variety of ways. Guaranteeing market access and establishing the principle of non-discrimination are

${ }^{1}$ See House of Lords European Union Committee Beyond Brexit: Trade in Services (HL Paper 248, March 2021) at 3 ('Beyond Brexit'); and Department for International Trade, UK Trade in Numbers (February 2020).

2 See G Barrett, 'Brexit and the Free Movement of Services: Challenges and Regulatory Solutions' in F Kainer and R Repasi (eds), Trade Relations after Brexit (Nomos/Hart 2019) 213 at 213. 
thus not sufficient to liberalize trade in services. Instead, these elements are only the start of what is needed. As Jacobsson has observed, 'in practice, the biggest market access barriers often take the form of various authorisation, licensing or certification requirements'. ${ }^{3}$ Mutual recognition of professional qualifications and securing the free movement of persons may also be key, depending on the services being traded.

Perhaps in consequence of this, the Single European Market in services (while still managing to be the most integrated international single market in services in the world) is less integrated than that in goods. Integration even on this more limited scale involves trust by the member states, mutual scrutiny and a certain level of harmonization. ${ }^{4}$

In the absence of UK government willingness to tolerate such prerequisites for integration post-Brexit, it was never likely that a high level of EU-UK co-operation concerning services would emerge from the Brexit negotiations. A serious deterioration in the conditions for EUUK cross-border provision of services was thus foreseeable - and that is exactly what has occurred, although, as shall be seen, there are mitigating factors cushioning the impact on cross-border economic relations on the island of Ireland.

There were, however, reasons for the failure to reach a better deal on services other than UK unwillingness to countenance the kinds of trade-offs in terms of, for example, regulatory alignment and free movement of persons that were needed to create agreement on a significant deal. The attitude of the EU also had a role to play: after all, negotiations on the economic conditions of an exit from the EU are, in reality, similar to those on entry to the EU - they represent less a negotiation than an imposition of the terms that the EU deems fit. EU views about the need for linkage between market freedoms and associated wariness about the dangers of British cherry-picking and, for that matter, aversion to being seen to be rewarding Brexit likely also played a role. In addition, some reticence on the EU side (for example, in the field of financial services) can fairly be attributed to commercial rivalry. Finally, the considerable time-pressure imposed by Prime Minister Boris Johnson's government to 'get Brexit done' may have complicated the cause of a more comprehensive services deal.

${ }^{3} \mathrm{~J} J a c o b s s o n$, Brexit and the Professional Services Sector - What Future for UK Professionals in Europe? (DCU Brexit Institute Working Paper 01-2020).

${ }^{4}$ Ibid, 10. 


\subsection{The Brexit Deal}

Whatever the reason, in the Brexit settlement, the free movement of services is notable as a dog that didn't bark. ${ }^{5}$ The Withdrawal Agreement (WA) contains relatively little on services, although it did provide for the continued application of the acquis - including the rules on services during the transition period. ${ }^{6}$ The Protocol, for its part, is hugely focused on free movement of goods (an issue that has continued to dominate political controversy in the wake of its entry into force). ${ }^{7}$ In contrast to its position concerning goods, Northern Ireland's place otherwise remains unequivocally aligned within the UK Single Market. Protocol Article 3 does, however, oblige the UK to ensure that the Common Travel Area (CTA) can continue to apply. This is significant regarding services in that the existence of the CTA counteracts one of the most severe restrictions on the free movement of services between the UK and Ireland as a whole, namely the restrictions on the free movement of persons.

The Trade and Cooperation Agreement (TCA) deals more extensively with services and investment, ${ }^{8}$ although what is left out of the TCA is as interesting as what it includes. Financial services and audiovisual services, both of major importance to the UK, are omitted, although a brief Joint Declaration ${ }^{9}$ does envisage a Memorandum of Understanding to establish a framework for structured regulatory cooperation on financial services. Such a memorandum was duly concluded in late March 2021. ${ }^{10}$

Even for the services covered by it, however, the TCA's offerings have proved thin fare, offering to trans-frontier service trade providers and investors merely the usual free trade agreement (FTA) market access plus national treatment commitments. This is far removed from a single

${ }^{5}$ Arthur Conan Doyle, The Memoirs of Sherlock Holmes (Collins Classics 2016) 10.

${ }^{6}$ See Art 127(1).

7 Six articles (Arts 4-8 and 10) focused heavily on goods. Only Arts 9 (focusing on the Single Electricity Market) and 11 (which mentioned co-operation in fields including health, transport, education and tourism) had much to do with services.

${ }^{8}$ Part 2, Heading One, Title II TCA. See I Borchert and M Morita-Jaeger, Taking Stock of the UK-EU Trade and Cooperation Agreement: Trade in Services and Digital Trade (UK Trade Policy Observatory Briefing Paper 53, January 2021).

9 Joint Declaration on Financial Services Regulatory Cooperation between the European Union and the United Kingdom.

${ }^{10} \mathrm{~J}$ Brunsden and P Foster, 'UK and EU Reach Financial Regulation Deal in Breakthrough on Cooperation' Financial Times (26 March 2021). A Joint UK-EU Financial Regulatory Forum was established to operate as a platform facilitating dialogue regarding financial services issues. 
market in services. ${ }^{11}$ Major service sectors such as professional and business services, ${ }^{12}$ financial services, aviation and road haulage now face substantial new barriers (even if there was some effort to show ambition in the fields of telecommunications, digital trade and international maritime trade). ${ }^{13}$

Moreover, and crucially, the TCA's offerings are subject to an impressive (and expandable ${ }^{14}$ ) list of European and national reservations. This factor distinguishes trade in goods from trade in services, since it means that for Northern Ireland service providers (and other UK providers) exporting into the $\mathrm{EU}$, the target market has now fragmented and they have suddenly found themselves selling into a patchwork of national markets. Fundamentally differently from the case in goods (where Northern Irish goods may move freely to the EU market and goods supplied to the EU market from Great Britain meet customs and health or veterinary requirements which are valid throughout the EU), the member state in which Northern Irish services are being sold now takes on crucial significance. For small businesses, inherently less able to absorb costs as they are, ${ }^{15}$ the very fact of fragmentation constitutes a barrier, and the complexity is even greater than first meets the eye since the reservation by each member state merely creates a right: in practice, reliance may or may not be made of this right. ${ }^{16}$

The TCA has been described as 'a comprehensive Canada-style free trade deal..$^{17}$ In some respects, the TCA actually improves on the EUCanada Comprehensive Economic and Trade Agreement (CETA), ${ }^{18}$ but in many respects it does indeed resemble earlier FTAs agreed by the European Union. This is not necessarily indicative of much significance, however. Hence, for example, even if CETA contains the EU's most ambitious provisions on mutual recognition of professional qualifications,

11 See further Borchert and Morita-Jaeger (n 8) 2.

12 At least where these are heavily regulated.

13 Borchert and Morita-Jaeger (n 8) 2.

14 TCA Annex 19 sets out reservations currently in force. TCA Annex 20 allows both the EU and the UK to adopt new reservations in stipulated fields in the future.

${ }^{15}$ Note evidence given by the Federation of Small Businesses to the House of Lords in this regard: see Beyond Brexit (n 1) 25.

16 Ibid, 24.

17 Prime Minister Boris Johnson's statement on EU negotiations of 24 December 2020 quoted in S Fella et al, The UK-EU Trade and Cooperation Agreement: Summary and Implementation (Briefing Paper 09106, 30 December 2020), 16.

18 Thus, eg, TCA provisions on legal services go beyond earlier FTAs. See generally Part 2, Heading One, Title II, s 7 of the TCA. 
it is a barely used framework, and one which stands out only because of a barren landscape at international level. Outside the 'complex system of mutual trust and mutual spying' that has allowed professional mutual recognition agreements to flourish within the $\mathrm{EU},{ }^{19}$ such agreements are almost unknown and negotiated only painfully slowly.

As regards limits on mobility of persons, the TCA establishes a mutual regime involving various categories of business visitor with varying rights to enter and reside - from (a) short-term business visitors to (b) business visitors for establishment purposes to (c) intra-corporate transferees to contractual service providers to (d) independent service providers. ${ }^{20}$ Stays of varying maximum duration are permissible, depending on which category one falls into. Short-term business visitors, for example, may enter for no more than 90 days in any 180-day period. Apart from length-of-stay limits, there may also be work permit or visa requirements and even economic needs tests, depending on what national reservations have been made. ${ }^{21}$ The overall impact of these new restrictions can be expected to be severe: after all, business travel saw 5.6 million EU nationals visit the UK in 2019 and 4.8 million UK nationals visit the EU. ${ }^{22}$

Securing recognition of professional qualifications has accurately been characterized as being as crucial as market access, ${ }^{23}$ but EU-wide mutual recognition has now ended with the TCA. UK nationals are thirdcountry nationals in the EU and now have to seek recognition for their professional qualifications through reliance on national EU member state rules. ${ }^{24}$ In addition, there are limits that stem from the loss of mutual recognition of home state standards (seen in particular in the ending of passporting in the financial services sector (discussed in Section 24.4.2)). While there are ways around some of these limitations, such as, for example, establishing a business or branch within the EU which might profit from free movement rights, such remedies tend to be less open to

19 K Nicolaides, 'Mutual Recognition: Promise and Denial, from Sapiens to Brexit' (2017) 70 Current Legal Problems 1 as quoted by Jacobsson (n 3) 12.

${ }^{20}$ See TCA Annex 21. Discussed in Beyond Brexit (n 1) 28 et seq.

${ }^{21}$ See generally Borchert and Morita-Jaeger (n 8).

22 Ibid, 27.

${ }^{23}$ Ibid.

${ }^{24}$ See European Commission, Notice to Stakeholders; Withdrawal of the United Kingdom and EU Rules in the Field of Regulated Professions and the Recognition of Professional Qualifications (Brussels, 21 June 2018). See also I Jozepa, UK-EU Trade and Cooperation Agreement; Professional Qualifications (House of Commons Briefing Paper 9172, 25 March 2021) ('Jozepa') at 1; and Anon, UK-EU Trade and Cooperation Agreement: Implications for Universities (Universities UK analysis, 22 April 2021). 
small businesses. This is no small matter on the island of Ireland, given the dominance of small and medium-sized enterprises (SMEs) in both jurisdictions and given the fact that the EU tends to be the biggest trading bloc for them. ${ }^{25}$

\subsection{Moderating the Effect of the Brexit Services Deal in Ireland}

At least four factors should, however, combine to moderate the impact of Brexit on service provision on the island of Ireland: (i) the fact that Ireland has made comparatively little use of reservations to the general provisions of the TCA; (ii) the fact that limitations on residence which would otherwise hamper the provision of services in Ireland from Northern Ireland will be removed because of the operation of the CTA; (iii) the fact that the similarity of professional regulations in Northern Ireland and Ireland eases the cross-border provision of services in both directions; and (iv) the fact that the Irish government is determined to limit the impact of Brexit, to the extent that it is able.

\subsubsection{Reservations}

Such national reservations as exist in Ireland appear primarily designed merely to facilitate existing provisions in Irish domestic law rather than to add to them. ${ }^{26}$ However, Ireland does benefit from quite a few general reservations which modify the open-seeming nature of the EU's commitments regarding services, ${ }^{27}$ and both these EU-wide reservations and the complex matrix of other national reservations ${ }^{28}$ will clearly detract from Northern Irish access to the services market, something that will impinge in particular on small businesses which lack the resources to invest in clarifying the rules that apply to a given EU member state market. But the

${ }^{25}$ See Central Statistics Office, Statistical Yearbook of Ireland; Northern Ireland Statistics and Research Agency, Northern Ireland Business; Activity, Size and Location: 2019.

${ }^{26}$ Hence, eg, the Irish reservation regarding intellectual property rights, reflecting the provisions of the Trade Marks Act 1996 (see OJ L444/14 (31.12.2020) at 579-80) and the Irish reservation concerning road transport, which reflects the provisions of the Public Transport Regulation Act 2009 (ibid, 642-43).

27 See, eg, the EU reservation allowing less favourable treatment of legal persons that have only a registered office in the EU without, however, having any effective and continuous link there (see OJ L444/14 (31.12.2020) at 560).

${ }^{28}$ See, eg, the extensive list of national reservations regarding legal services (see OJ L444/14 (31.12.2020) at 569); and regarding placement services (ibid, 691). 
Irish market will be one in which a general EU regime is likely to apply to the maximum extent.

\subsubsection{Common Travel Area}

Restrictions on the free movement of persons flowing from Brexit can be expected to have a damaging effect on the creative industries in particular, making the organization of Europe-wide tours for Northern Irish performers nightmarishly complex, especially for performers at the beginning of their careers who may not have the resources to address twenty-seven different sets of rules. The CTA renders possible indefinite residence by Irish nationals in the UK and vice versa, and while the existence of the CTA thus does not eliminate Brexit-related difficulties for Northern Irish performers, it means at least that they will not be encountered in service provision to customers in Ireland. ${ }^{29}$ The role of the CTA in counteracting difficulties at least in these islands actually goes beyond this, particularly as regards the recognition of professional qualifications. ${ }^{30}$ Thus, in the context of the British Isles and Ireland, common travel arrangements are being relied on as a basis for filling lacunae created by the failure to agree more substantive free movement of services arrangements in the TCA - and lacunae relating to not just residence arrangements but qualifications, too.

\subsubsection{Similarity of Professional Regulations and Legal Structures}

In the absence of an EU-wide system of recognition of professional qualifications, the UK may find itself relying across Europe on arrangements between national regulators. UK authorities should find it easier to reach agreement with Ireland on recognizing each other's professional qualifications than with other EU jurisdictions. Discussions to this end commenced between Ireland and the UK early in 2021. Pending the more comprehensive arrangements that may result, agreements have been reached concerning architects and lawyers. ${ }^{31}$ The similarity of national

29 On the CTA, see G Barrett and G Butler, 'Europe's "Other” Open-Border Zone: The Common Travel Area under the Shadow of Brexit' (2018) 20 Cambridge Yearbook of European Legal Studies 252; and I Maher, 'Crossing the Irish Law Border after Brexit: The Common Travel Area and the Challenge of Trade' (2018) Irish Yearbook of International Law 51.

30 See Department for Business, Energy and Industrial Strategy, Recognition of Professional Qualifications: Guidance for Regulatory Bodies (published on the gov.uk website, 23 December 2020).

31 The UK Architects Registration Board has concluded a bilateral agreement with the Royal Institute of Architects of Ireland ensuring continued mutual recognition of qualifications. 
legal structures - whether for enterprises or in terms of professional structures - should facilitate and accelerate mutual recognition and the establishment of enterprises or branches in both directions so as to avoid Brexit-related difficulties. And the CTA both encourages mutual cooperation to address barriers and forms a nascent institutional framework within which such cooperation may occur.

\subsubsection{Irish Government Action on Services}

A further factor moderating the impact of Brexit in the services field is the clear willingness on the part of the authorities in the Republic to limit the impact of Brexit. The most obvious example is in the field of educational services, where the Irish government has undertaken to finance the continued access of Northern Irish students to the Erasmus+ programme. A similar proposal to provide Northern Ireland residents with continued access to the European Health Insurance Card was not, however, accepted by the UK. ${ }^{32}$

\subsection{The Impact of Brexit on Particular Service Sectors}

\subsubsection{Professional Services and Brexit}

One of the areas in which Brexit can be expected to have the biggest impact on cross-border service provision in Ireland is professional and business services, which are the UK's single biggest export, and of which the UK is the second largest exporter in the world. ${ }^{33}$ The provision of these services has been subjected to a double-blow: restrictions on free movement of persons have now been introduced; and recognition of professional qualifications as between EU states and the UK has been withdrawn, recognition which was particularly important for regulated industries such as medicine, law, accountancy and architecture. ${ }^{34}$

We have seen that the CTA can alleviate the first of these blows, insofar as the relationship between Northern Ireland and Ireland is concerned, by allowing the movement of professionals between the jurisdictions more easily than would otherwise be the case. Moreover, the possibility of

Beyond Brexit (n 1) 33. The Law Society of Ireland and the UK Solicitors Regulation Authority have acted similarly rapidly. O Kelly, 'Irish Solicitors Will Be Able to Work in England, Wales' Irish Times (1 April 2021).

32 See further in relation to both initiatives Dagmar Schiek, Brexit and the Implementation of the Withdrawal Agreement (DCU Brexit Institute Working Paper 9 - 2021), at 11 and 13.

33 See Beyond Brexit (n 1) 21. See also Jozepa (n 24).

34 Unregulated industries are less severely impacted by the new regime. 
Northern Irish firms establishing an undertaking or branch in the Republic and thereby avoiding restrictions should be rendered comparatively easier in any case by similarly conceived regulations, legal structures and educational and professional qualifications between the jurisdictions. We saw, too, that the second new difficulty - recognition of qualifications - is harder to deal with, but, again, the regulatory similarity between the jurisdictions should render the mutual recognition of national qualifications by the respective regulators an easier process than would otherwise be the case. The same similarity should also render it easier for regulators to agree that Northern Irish members of regulated professions can requalify with an EU (Irish) qualification without having to undergo the entire period of training again.

Such initiatives may alleviate the negative impact of the Brexit deal on Northern Irish service providers only as regards providing services to Ireland, however, not to other EU states. There is, it should be noted, a more general mechanism which foresees pan-European mutual recognition of qualifications, but the record of such clauses in other FTAs in securing change is not good. Moreover, in the event of violations of the TCA, the new state-to-state enforcement method is more cumbersome than the pre-Brexit possibility of relying on national courts and tribunals for relief. Overall, it can be expected that small firms - which might, for example, find it harder to find the resources to establish a branch office in the EU - will be hit harder in the post-Brexit scenario than larger ones.

\subsubsection{Financial Services and Brexit}

Financial services are an important service industry, in Ireland, ${ }^{35}$ in Northern Ireland ${ }^{36}$ and particularly in the UK. ${ }^{37}$ Notwithstanding the importance of that industry, remarkably, the TCA represents a 'no deal' Brexit: ${ }^{38}$ the Agreement lacks any substantive provisions regarding financial services, although it was accompanied by a Joint Declaration (and later Memorandum of Understanding) which eventually generated a structure for dialogue. There is no guarantee, however, that the

35 See further www.idaireland.com/doing-business-here/industry-sectors/financialservices.

36 Department for the Economy, Mapping NI's Financial Services Sector, www.economyni.gov.uk/articles/mapping-nis-financial-services-sector.

37 House of Commons Library, Financial Services: Contribution to the UK Economy (Library Note 6193, 1 February 2021).

38 See N Moloney, Financial Services under the Trade and Cooperation Agreement: Reflections on Unfinished Business for the EU and UK (DCU Brexit Institute Working Paper 3-2021) at 2. 
dialogue thereby generated will be of much significance, and expectations appear low. Key decisions, such as on equivalence, have not been forthcoming on the EU side. Financial services thus remain in a period of uncertainty. ${ }^{39}$

Post-Brexit, at least, two major issues have featured in the narrative. The first is the loss of passporting (the mutual recognition of home state financial regulations) to the UK in selling financial services into the EU market and its potential replacement with the unilateral, Commissionaccorded, discretionary system of equivalence (requiring, more or less, alignment with EU rules). The EU uses this legislation-based system to manage access by third countries to its financial market. ${ }^{40}$ Any equivalence decisions in favour of the UK are likely to be accorded slowly, and will be granted only if and when it suits the EU's interests to grant them. A second, related issue has been the desire of the EU to see central counterparties move to the territory of the EU. ${ }^{41}$ At present, much eurodenominated clearing takes place in the UK, but this situation seems scarcely tenable in the near term, perhaps, as has been suggested, as much for market location reasons as for market efficiency ones. ${ }^{42}$

The future trajectory of financial services provision in the UK thus remains uncertain, with the key question being whether the City of London will align itself to European standards or diverge. ${ }^{43}$ The ultimate picture seems likely to emerge only gradually. There will clearly be no immediate bonfire of financial service regulations by the UK. ${ }^{44}$ A gradual drift from full alignment may nonetheless set in, perhaps encouraged by the UK tiring of the wait for equivalence to be granted. ${ }^{45}$ Mechanisms exist for avoiding post-Brexit restrictions on UK service providers. These include the establishment of an undertaking or branch in an EU jurisdiction, the replacement of UK service providers with Irish ones, and the redomiciling of investment products.

What effect has the changed situation had on the island of Ireland? Reflecting the uncertainty regarding the market trajectory, the existence of the possibility of establishing bases in the EU, and yet the

39 Beyond Brexit (n 1) 12.

40 Moloney (n 38) 3.

41 Central counterparties provide clearing services for trades in various financial products. In doing so, they take on the credit risk as between the parties to a transaction.

42 Moloney (n 38) 15.

43 Ibid, 3.

44 Note the UK government assurance referred to in Beyond Brexit (n 1) 63.

45 See P Stafford, 'UK and EU Begin Diverging on Financial Regulation after Brexit' Financial Times (26 March 2021). 
countervailing need not to abandon the UK, a significant, if comparatively modest, level of businesses shifting to Dublin has been reported (although seemingly more from London than from Belfast to date), ${ }^{46}$ accompanied by even more modest and little remarked-upon traffic in the other direction. ${ }^{47}$ Some movement of business is also taking place in the direction of other financial centres such as the USA, which has secured an easier equivalence relationship with the EU.

\subsubsection{Creative Industries and Brexit}

The creative service industries, which include music and television, have been left in some cases in very considerable difficulties by Brexit, and for more than one reason. Probably the most prominent reason is the restrictions which the TCA has introduced concerning the free movement of persons, which place extraordinarily harsh restrictions on groups, particularly those seeking to build up a public profile at an early career stage by touring. The effect, except for the most well-resourced groups, has been to render touring in the EU well-nigh impossible for UK groups. ${ }^{48}$ There is a danger of thereby stifling artistic creativity. ${ }^{49}$ As we have seen, because of the CTA, such restrictions do not apply to UK (including Northern Irish) groups seeking to tour in Ireland. However, the Irish market is small and thus the Brexit deal's having a deleterious effect on Northern Irish musical groups seems probable. Furthermore, the impact of potential divergences between the EU and the UK on copyright protection remains unclear.

\subsubsection{Research and Education}

In the research field, the UK has opted into Horizon Europe, which is likely to have positive effects for research in Ireland as well, given the close academic links between the two jurisdictions. As has already been noted, the Irish government has agreed to finance participation on the

46 See N Bramhill, 'Dublin Benefitting More Than Any Other EU City Due to Brexit' Irish Central (22 April 2021); C Gleeson, 'Dublin Most Popular City for Brexit Relocations by Financial Firms' Irish Times (2 March 2021); W Wright, 'Brexit Has Cost the City $£ 1$ tn in Assets and 7400 Jobs So Far, Report Finds’ Evening Standard (16 April 2021).

47 See 'City of London Hit Worse Than Expected, Says Study' Euractiv (13 May 2021). See also Beyond Brexit (n 1) 11.

48 The UK rejected an EU proposal of a visa waiver agreement to facilitate touring in the negotiations.

49 A point acknowledged in Beyond Brexit (n 1) 8. 
part of students in Northern Irish universities in the Erasmus+ scheme of student exchanges.

\subsection{Conclusions}

Overall, the TCA services deal was welcomed by UK business, although perhaps mostly because the alternative was no deal at all. ${ }^{50}$ Post-Brexit, 'the all-Ireland services market has shaky legal foundations'. ${ }^{51}$ Unlike the situation in goods, there is now a border on the island of Ireland, albeit an invisible one (that is, one which, unlike in the goods field, does not require border controls). It is, mercifully, a somewhat 'soft' border for several other reasons as well. First, the Single Market in services itself is less solid than that existing in goods. Second, this border can sometimes be avoided by establishing undertakings or branches on the other side of the border, or obtaining the relevant professional qualification needed there. Third, several factors should combine to moderate some of the damage done to the unified services market by Brexit. To some extent, Ireland may function as a stepping-stone for the access of Northern Irish (and UK) service providers to the Single Market by permitting establishment and mutual recognition of professional qualifications in an EU member state with the same legal and organizational culture and using the same language.

Not all damage can be undone in this way, however, and not every element of the all-island market in services formerly secured through UKEU membership can be reconstituted by such means. Small enterprises in particular are badly placed to resist suffering economic hardship. Many implications of Brexit do not directly bear on the relationship between Northern Ireland and the Republic, but they have the capacity to impact that relationship indirectly by undermining prosperity in particular in Northern Ireland and in border areas. Moreover, any serious damage to the UK economy through the replacement of what was formerly a single market with a complex fragmented patchwork of individual national markets can be expected to have some ripple effects in the Irish economy.

Politically, the issue of services is less explosive than that of goods on the island of Ireland, since services do not threaten to function like a lever prising Northern Ireland away from economic and potentially political unity with the UK. Economically, however, services are of far greater significance, meaning that Brexit is of greater potential economic

50 George Riddell of Ernst and Young quoted in Beyond Brexit (n 1) 3.

51 A phrase coined in a thread tweeted by D Henig @DavidHenigUK, 26 February 2020. 
significance for Northern Ireland in the long term through threatening its access to an important unified European market for services, than for any direct negative consequences related to goods. The focus of political debate has remained squarely on the free market for goods, but if prospects for economic prosperity are hurt by Brexit, one suspects that this will be in no small measure due to damage Brexit inflicts on the most important economic sector both north and south of the border: the services industry. 